Article

\title{
Gas-Phase Thermal Tautomerization of Imidazole-Acetic Acid: Theoretical and Computational Investigations
}

\author{
Saadullah G. Aziz ${ }^{1, \dagger}$, Osman I. Osman ${ }^{1,2, \dagger, *}$, Shaaban A. Elroby ${ }^{1,3, \dagger}$ and Rifaat H. Hilal ${ }^{1,4, \dagger}$ \\ Received: 7 August 2015 ; Accepted: 22 October 2015 ; Published: 4 November 2015 \\ Academic Editor: Henry Chermette \\ 1 Chemistry Department, Faculty of Science, King Abdulaziz University, P.O. Box 80203, Jeddah 21589, \\ Saudi Arabia; saziz@kau.edu.sa (S.G.A.); skamel@kau.edu.sa (S.A.E.); rhilal@kau.edu.sa (R.H.H.) \\ 2 Chemistry Department, Faculty of Science, University of Khartoum, P.O. Box 321, Khartoum 11111, Sudan \\ 3 Chemistry Department, Faculty of Science, Beni-Suef University, Beni-Suef 62511, Egypt \\ 4 Chemistry Department, Faculty of Science, Cairo University, Giza 12613, Egypt \\ * Correspondence: oabdelkarim@kau.edu.sa; Tel.: +966-1-2695-1795; Fax: +966-1-2695-2709 \\ $\dagger \quad$ These authors contributed equally to this work.
}

\begin{abstract}
The gas-phase thermal tautomerization reaction between imidazole-4-acetic (I) and imidazole-5-acetic (II) acids was monitored using the traditional hybrid functional (B3LYP) and the long-range corrected functionals (CAM-B3LYP and wB97XD) with 6-311++G** and aug-cc-pvdz basis sets. The roles of the long-range and dispersion corrections on their geometrical parameters, thermodynamic functions, kinetics, dipole moments, Highest Occupied Molecular Orbital-Lowest Unoccupied Molecular Orbital (HOMO-LUMO) energy gaps and total hyperpolarizability were investigated. All tested levels of theory predicted the preference of I over II by $0.750-0.877 \mathrm{kcal} / \mathrm{mol}$. The origin of predilection of $\mathrm{I}$ is assigned to the H-bonding interaction $\left(\mathrm{n}_{\mathrm{N} 8} \rightarrow \sigma^{*} \mathrm{O14}-\mathrm{H} 15\right)$. This interaction stabilized I by $15.07 \mathrm{kcal} / \mathrm{mol}$. The gas-phase interconversion between the two tautomers assumed a 1,2-proton shift mechanism, with two transition states (TS), TS1 and TS2, having energy barriers of 47.67-49.92 and 49.55-52.69 kcal/mol, respectively, and an $\mathrm{sp}^{3}$-type intermediate. A water-assisted 1,3-proton shift route brought the barrier height down to less than $20 \mathrm{kcal} / \mathrm{mol}$ in gas-phase and less than $12 \mathrm{kcal} / \mathrm{mol}$ in solution. The relatively high values of total hyperpolarizability of I compared to II were interpreted and discussed.
\end{abstract}

Keywords: imidazole-4-acetic acid; tautomerization; long-range; dispersion

\section{Introduction}

Imidazole is a heterocyclic polar organic compound. Its 5-membered ring is planar. It has two tautomers because the proton can be linked with any of the two nitrogen atoms. Imidazole exists in many biologically important compounds like histidine and histamine [1]. Imidazoleacetic acid is one of the most important derivatives of imidazole. It is one possible paths of histamine metabolism by being an intermediate in the physiological oxidation of histamine [2]. It has two well-known isomers: imidazole-4-acetic acid and imidazole-5-acetic acid, which are isolated in the laboratory as hydrochlorides or sodium salts [3]. The former occurs naturally in the brain as a metabolite of histamine oxidation [4]. It was prepared, in the laboratory, from the acid hydrolysis of cyanomethylimidazole, which is made from chloromethylimidazole [5]. Its neuropharmacological functions include enhancing the binding of benzodiazepine to $\gamma$-aminobutyric acid (GABA, its structural analogue) receptor complex in membrane preparations and acting as an antagonist through its affinity for GABA receptors [6]. On the other hand, imidazole-5-acetic acid derivatives have 
anti-inflammatory activities [7], an antagonistic effect on the peptide hormone, angiotensin II, in addition to some hypotensive activities. They are also useful as hypotensive agents [8].

Another very important application of imidazole-4-acetate anion is its affinity for transition metal cations forming complexes via bonding through the carboxylic oxygen and the un-protonated imidazoline nitrogen atoms $[9,10]$. Imidazole-5-acetate anions are hindered from binding with the transition metal cations as the position of the donor oxygen and nitrogen atoms do not facilitate chelation [11].

These vital biological, pharmacological, and physicochemical applications of imidazoleacetic acid have caught the attention of many researchers [9-11]. Our contribution here is to shed more light on the geometric structures of its conformers, the interconversion of its tautomers and their kinetic and thermodynamic stabilities. Their non-linear optical (NLO) properties were also investigated and supported by natural bond orbital (NBO) analysis.

\section{Results and Discussion}

\subsection{Molecular Structure}

Figure 1 shows the atom numbering for the different conformers of imidazoleacetic acid, I and II (See their standard coordinates in Tables S1 and S2). Tables 1 and 2 list the gas-phase optimized bond lengths (see Figure 2), and bond angles of I and II which have been estimated by using B3LYP, CAM-B3LYP, and $\omega B$ 97XD functionals with 6-311++G** and aug-cc-pvdz basis sets; together with those extracted from Imidazoleacetic acid hydrochloride crystal structure [12]. Apart from the $\mathrm{C} 2-\mathrm{C} 3-\mathrm{N} 4$ angle, all bond lengths and angles obtained for the two studied compounds, using all elected levels of theory, are comparable [13]. The C2-C3-N4 angle is $c a .5^{\circ}$ larger for the I than for II tautomer, is in good agreement with a theoretical investigation of histamine tautomerism [14]. On the one hand, the hybrid functional (B3LYP) gave longer bond lengths compared to the LC-DFT functionals (CAM-B3LYP and $\omega B$ 97XD); while the $6-311++G^{* *}$ basis set yielded longer bond lengths compared to those obtained from aug-cc-pvdz basis set. On the other hand, the bond angles are insensitive to the applied level of theory, in agreement with a study conducted by Wiberg [15].

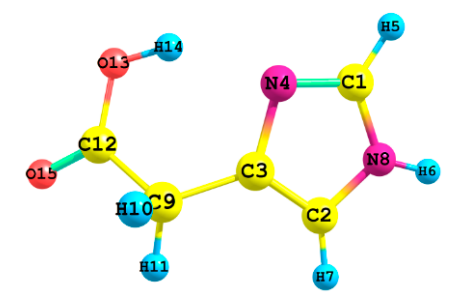

Figure 1. The atom numbering of imidazole-4-acetic acid.

Table 1. The bond lengths ( $\AA$ ) of the optimized geometries of H-bonded imidazole-4-acetic acid (I) and imidazole-5-acetic acid (II) using B3LYP, CAM-B3LYP and $\omega$ B97XD functionals with $6-311++\mathrm{G}^{* *}$ (three top lines) and aug-cc-pvdz (three bottom lines) basis sets. The crystal structure of imidazole-4-acetic acid hydrochloride is given for comparison purposes.

\begin{tabular}{|c|c|c|c|c|c|c|c|c|c|c|c|c|}
\hline \multirow{2}{*}{$\begin{array}{l}\text { Level of } \\
\text { Theory }\end{array}$} & \multicolumn{2}{|c|}{ C1-N4 } & \multicolumn{2}{|c|}{ C1-N8 } & \multicolumn{2}{|c|}{ C2-N8 } & \multicolumn{2}{|c|}{ C2-C3 } & \multicolumn{2}{|c|}{ C3-N4 } & \multicolumn{2}{|c|}{ C3-C9 } \\
\hline & $T$ & III & $T$ & III & $T$ & III & $T$ & III & $T$ & III & $=$ & II \\
\hline B3LYP & 1.315 & 1.314 & 1.359 & 1.364 & 1.382 & 1.379 & 1.370 & 1.375 & 1.382 & 1.376 & 1.498 & 1.500 \\
\hline CAM-B3LYP & 1.308 & 1.306 & 1.353 & 1.359 & 1.377 & 1.374 & 1.363 & 1.366 & 1.377 & 1.372 & 1.494 & 1.493 \\
\hline$\omega B 97 X D$ & 1.310 & 1.308 & 1.353 & 1.359 & 1.377 & 1.374 & 1.365 & 1.368 & 1.377 & 1.372 & 1.495 & 1.493 \\
\hline B3LYP & 1.319 & 1.312 & 1.361 & 1.360 & 1.383 & 1.375 & 1.376 & 1.372 & 1.384 & 1.374 & 1.500 & 1.494 \\
\hline CAM-B3LYP & 1.313 & 1.312 & 1.354 & 1.360 & 1.379 & 1.375 & 1.369 & 1.372 & 1.379 & 1.374 & 1.497 & 1.494 \\
\hline$\omega B 97 X D$ & 1.314 & 1.314 & 1.355 & 1.360 & 1.378 & 1.375 & 1.379 & 1.373 & 1.380 & 1.375 & 1.497 & 1.495 \\
\hline Expert $^{\mathrm{a}}$ & \multicolumn{2}{|c|}{1.318} & \multicolumn{2}{|c|}{1.323} & \multicolumn{2}{|c|}{1.375} & \multicolumn{2}{|c|}{1.355} & \multicolumn{2}{|c|}{1.378} & \multicolumn{2}{|c|}{1.479} \\
\hline
\end{tabular}


Table 2. The bond angles (degrees) of the optimized geometries of H-bonded imidazole-4-acetic acid (I) and imidazole-5-acetic acid (II) using B3LYP, CAM-B3LYP, and $\omega$ B97XD functionals with $6-311++G^{* *}$ (three top lines) and aug-cc-pvdz (three bottom lines) basis sets. The crystal structure of imidazole-4-acetic acid hydrochloride is given for comparison purposes.

\begin{tabular}{|c|c|c|c|c|c|c|c|c|c|c|}
\hline \multirow{2}{*}{$\begin{array}{l}\text { Level of } \\
\text { Theory }\end{array}$} & \multicolumn{2}{|c|}{ N8-C1-N4 } & \multicolumn{2}{|c|}{ C1-N8-C2 } & \multicolumn{2}{|c|}{ N8-C2-C3 } & \multicolumn{2}{|c|}{ C3-N4-C1 } & \multicolumn{2}{|c|}{ C2-C3-N4 } \\
\hline & I & II & I & II & I & II & I & II & I & II \\
\hline B3LYP & 110.81 & 111.72 & 97.69 & 107.25 & 05.50 & 104.92 & 106.51 & 105.35 & 09.49 & 104.92 \\
\hline CAM-B3LYP & 110.85 & 111.75 & 107.61 & 107.17 & 105.53 & 105.05 & 106.51 & 105.40 & 109.48 & 105.05 \\
\hline$\omega B 97 X D$ & 110.99 & 111.88 & 107.63 & 107.17 & 105.44 & 105.02 & 106.29 & 105.22 & 109.64 & 105.02 \\
\hline B3LYP & 110.78 & 111.69 & 107.81 & 107.42 & 105.46 & 104.88 & 106.49 & 105.29 & 109.46 & 104.88 \\
\hline CAM-B3LYP & 110.84 & 111.72 & 107.74 & 107.34 & 105.49 & 105.01 & 106.48 & 105.34 & 109.45 & 105.01 \\
\hline$\omega \mathrm{B} 97 \mathrm{XD}$ & 110.97 & 111.84 & 107.74 & 107.32 & 105.42 & 104.98 & 106.37 & 105.16 & 109.60 & 104.98 \\
\hline Expert $^{a}$ & \multicolumn{2}{|c|}{108.0} & \multicolumn{2}{|c|}{109.2} & \multicolumn{2}{|c|}{107.0} & \multicolumn{2}{|c|}{109.8} & \multicolumn{2}{|c|}{106.0} \\
\hline
\end{tabular}

a Taken from [12].

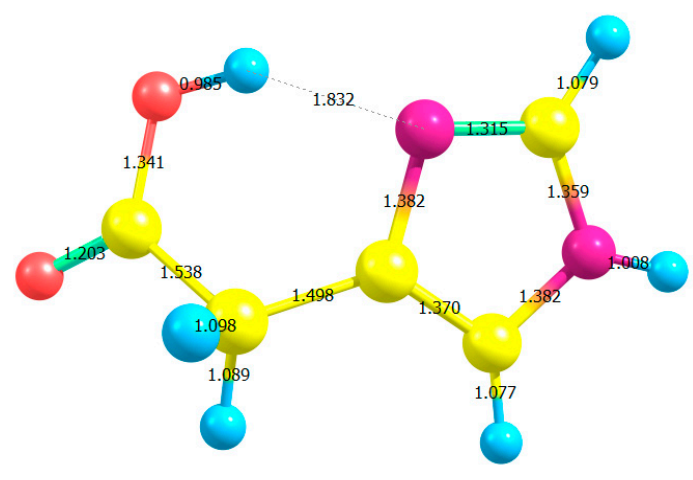

(a)

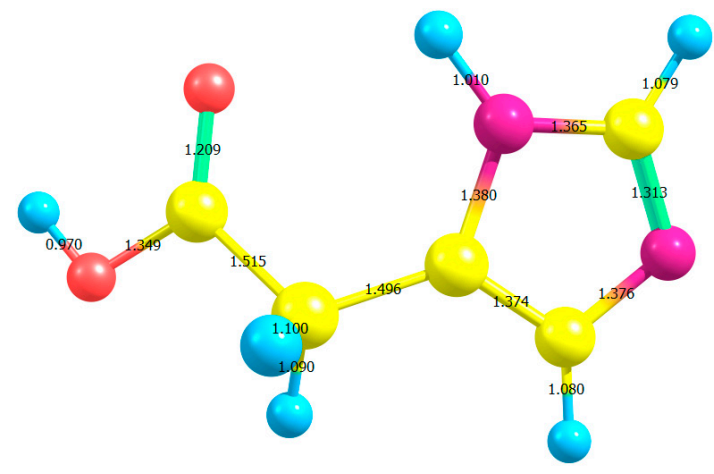

(b)

Figure 2. The optimized bond lengths of (a) H-bonded imidazole-4-acetic acid (I) and (b) imidazole-5-acetic acid (II) using B3LYP / 6-311++G** level of theory.

Tables S3-S5 list the bond lengths, bond angles and dihedral angles of I and II computed by B3LYP /6-3111++ $\mathrm{G}^{* *}$ level of theory. This is because this level of theory gives the most satisfactorily calculated geometrical parameters [15]. They were compared with those extracted from the crystal structure of Imidazole-acetic acid hydrochloride [12]. The absolute errors between the computed and measured values were also registered. The calculated bond lengths of the two substrates are comparable and, therefore, deviated almost equally from their crystal structure counterparts [12]. There is satisfactory agreement between the calculated and experimental bond lengths as indicated by the relatively small average error. The deviations between the calculated and measured bond angles and torsion angles are noticeable. These discrepancies could be explained by the different natures of the gas-phase and solid-phase geometries. The crystal structure intermolecular H-bonds could account, in part, for the large disparities between the calculated and experimental dihedral angles [16]. The largest percentage differences between the calculated and measured N8-C1 and C12-O13 bonds did not exceed ca. 3.1\%; while the largest error encountered in C9-C12-O13 angle was of the order of $c a .3 .5 \%$.

In Table 3 the optimized geometries of Imidazole-4-acetic acid (I) are listed that tautomerized to Imidazole-5-acetic acid (II) through two transition states (TS1 and TS2) and an $\mathrm{sp}^{3}$-type intermediate (INTER) which have been obtained by using B3LYP/6-311++G** level of theory (See Tables S6-S8). The tautomerization between I and II via these transitions states and the intermediate are depicted in Figure 3. They can be visualized through the following points: (1) The N4-H5 bond length of $1.008 \AA$ in I elongated by $0.294 \AA$ in TS1. It shortened and finally settled at $1.096 \AA$ as a C3-H5 bond in the 
INTER. This is the first step of the 1,2-proton shift; (2) Consequently, the C3-N4 and C3-N8 bond lengths of I of 1.359 and $1.315 \AA$, expanded by 0.094 and $0.032 \AA$ in TS1 and by another 0.022 and $0.108 \AA$ in the INTER, respectively. These geometrical changes fit nicely with the proposed $\mathrm{sp}^{3}$-type intermediate formation [17]; (3) The INTER C3-H5 bond length of 1.096 Å elongated by $0.246 \AA$ in TS2 and disappeared in II as a preparation for the second step of the 1,2-proton transfer; (4) The H5 proton then formed a partial bond with N8 of $1.310 \AA$, which finally settled as an N8-H5 bond (1.010 $)$ in II. These remarks will further be supported by a natural bond orbital (NBO) analysis.

Table 3. Some selected optimized bond lengths of H-bonded imidazole-4-acetic acid (I) that tautomerized forming imidazole-5-acetic acid (II) through two transition states (TS1 and TS2) and an $\mathrm{sp}^{3}$-type intermediate (INTER) which were obtained by using B3LYP/6-311++G** level of theory.

\begin{tabular}{|c|c|c|c|c|c|}
\hline Paramete & er I & TS1 & INTER & TS2 & II \\
\hline N4-H5 & 1.008 & 1.302 & - & - & - \\
\hline C3-N4 & 1.359 & 1.431 & 1.453 & 1.350 & 1.313 \\
\hline C3-H7 & 1.079 & 1.081 & 1.096 & 1.077 & 1.079 \\
\hline C3-N8 & 1.315 & 1.347 & 1.455 & 1.507 & 1.365 \\
\hline N8-C2 & 1.382 & 1.345 & 1.286 & 1.383 & 1.380 \\
\hline C3-H5 & - & 1.292 & 1.096 & 1.342 & - \\
\hline N8-H5 & - & - & - & 1.310 & 1.010 \\
\hline
\end{tabular}

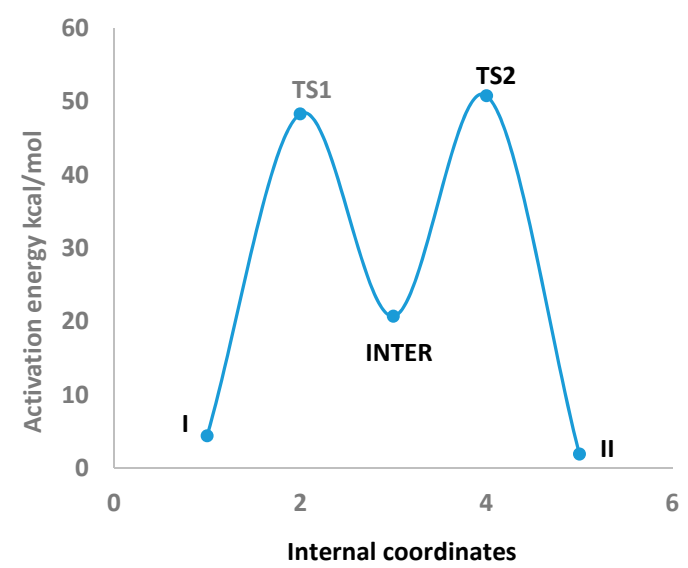

Figure 3. Intrinsic reaction coordinate (IRC) of the tautomerization of Imidazole-4-acetic acid (I) and Imidazole-5-acetic acid (II) through two transition states (TS1 and TS2) and an intermediate (INTER) which were obtained by using B3LYP/6-311++G** level of theory.

\subsection{Thermodynamic Analysis}

The values of $\Delta E, \Delta H, \Delta S, \Delta G$, and $K$ for the tautomerization reaction: $\mathrm{I} \leftrightarrow \mathrm{II}$ obtained by using B3LYP, CAM-B3LYP, and $\omega$ B97XD functionals with $6-311++\mathrm{G}^{* *}$ and aug-cc-pvdz basis sets are shown in Table 4.

Table 4. B3LYP, CAM-B3LYP and $\omega B 97 X D$ functionals with $6-311++G^{* *}$ and aug-cc-pvdz basis sets zero-point reaction energies, enthalpies, entropies, free energies, and equilibrium constants for the equilibrium $\mathrm{I} \leftrightarrow \mathrm{II}$ at $298.15 \mathrm{~K}$.

\begin{tabular}{|c|c|c|c|c|c|}
\hline Level of Theory & $\Delta E / \mathrm{kcal} / \mathrm{mol}$ & $\Delta H / \mathrm{kcal} / \mathrm{mol}$ & $\Delta S / \mathrm{cal} /(\mathrm{mol} \mathrm{K})$ & $\Delta G / \mathrm{kcal} / \mathrm{mol}$ & $K$ \\
\hline B3LYP $/ 6-311++G^{* *}$ & -0.802 & -0.952 & -1.981 & -0.361 & 1.84 \\
\hline CAM-B3LYP $/ 6-311++\mathrm{G}^{* *}$ & -0.750 & -0.903 & -1.905 & -0.335 & 1.76 \\
\hline$\omega B 97 X D / 6-311++G^{* *}$ & -0.863 & -0.976 & -1.406 & -0.557 & 2.56 \\
\hline B3LYP/aug-cc-pvdz & -0.877 & -1.039 & -2.033 & -0.433 & 2.08 \\
\hline CAM-B3LYP/aug-cc-pvdz & $\mathrm{z}-0.841$ & -1.000 & -2.127 & -0.423 & 2.04 \\
\hline$\omega B 97 X D /$ aug-cc-pvdz & -0.838 & -0.967 & -1.589 & -0.493 & 2.30 \\
\hline
\end{tabular}


All elected levels of theory favor I over II by $0.750-0.877 \mathrm{kcal} / \mathrm{mol}$, in excellent agreement with that obtained for the tautomers of nitro-imidazole of $0.760 \mathrm{kcal} / \mathrm{mol}$ using B3LYP $/ 6-31 \mathrm{G}^{*}$ level of theory [18]. Apparently, I is most favored when using $\omega B$ B7XD/6-311++ $G^{* *}$ level of theory. The inclusion of the long-range correction on the traditional hybrid B3LYP has led to the CAM-B3LYP functional [19]. The effect of the long-range correction parameter on $\Delta E$ is seen in Table 4 , in which B3LYP and CAM-B3LYP with 6-311++ $\mathrm{G}^{* *}$ and aug-cc-pvdz basis sets results are compared. In these two cases, including the long-range correction changes $\Delta E$ by 0.052 and $0.036 \mathrm{kcal} / \mathrm{mol}$, respectively. It brings about similar effects on $\Delta G$ of 0.026 and $0.010 \mathrm{kcal} / \mathrm{mol}$, respectively; which implies respective decreases of $K$ by 0.08 and 0.04 . The implication of damped atom-atom dispersion corrections on long-range corrected hybrid density functionals yields $\omega$ B97XD functional [20]. The effect of dispersion correction on $\Delta E, \Delta G$, and $K$ values are also listed in Table 4 , in which the results of CAM-B3LYP and $\omega$ B97XD functionals with $6-311++\mathrm{G}^{* *}$ and aug-cc-pvdz basis sets are compared. It is apparent that the dispersion correction lowers $\Delta E$ by $0.113 \mathrm{kcal} / \mathrm{mol}$ when using $6-311++\mathrm{G}^{* *}$, but it raises it by $0.003 \mathrm{kcal} / \mathrm{mol}$ when using aug-cc-pvdz basis set. In comparison, the dispersion-correction effect lowers $\Delta \mathrm{G}$ when using both $6-311++\mathrm{G}^{* *}$ and aug-cc-pvdz basis sets by 0.222 and $0.070 \mathrm{kcal} / \mathrm{mol}$ respectively; implying an increase of equilibrium constants at $298.15 \mathrm{~K}$ of $46 \%$ and $13 \%$, respectively.

$\Delta \mathrm{G}$ values at $298.15 \mathrm{~K}$ for all applied levels of theory are dictated mostly by $\Delta \mathrm{H}(61 \%-67 \%)$ with moderately less contribution from $\mathrm{T} \Delta \mathrm{S}(33 \%-39 \%)$. These percentage differences are attributed to long-range and dispersion corrections on functionals $[15,16]$, rather than by basis set effects. The equilibrium constants values at $298.15 \mathrm{~K}$ range between 1.76 and 2.56. They are in reasonable agreement with those calculated for 4-nitro-imidazole $\leftrightarrow 5$-nitro-imidazole equilibrium of 2.48 obtained from B3LYP $/ 6-31+G^{*}$ level of theory [13]. Their deviation from the experimental values of $0.45-1.5$ [21], is attributable to phase difference i.e., the experimental values are solution data, while ours are gas-phase estimates. Our calculated equilibrium values indicate that the equilibrium concentration of I is $c a$. twice that of II. The highest equilibrium concentration for I of more than 2.5 -fold compared to that of II was obtained by using $\omega \mathrm{B} 97 \mathrm{XD} / 6-311++\mathrm{G}^{* *}$ level of theory. The negative values of $\Delta S$ indicate the preference of I over II at all temperatures.

\subsection{Activation Energies}

In Table 5 the zero-point electronic and activation energies of the tautomerization reaction are listed: I $\leftrightarrow$ II. These parameters were computed by using B3LYP, CAM-B3LYP, and $\omega$ B97XD functionals with $6-311++G^{* *}$ and aug-cc-pvdz basis sets. The potential energy profile for this 1,2-proton shifts [17] tautomerization reaction applying B3LYP $/ 6-311++G^{* *}$ level of theory is depicted in Figure 3. This level of theory has been selected because a remarkable agreement between the highly accurate Complete Basis Set (CBS) method and the B3LYP /6-311++ $\mathrm{G}^{* *}$ level of theory was observed for computing the activation barriers of triazoles and tetrazoles [22]. The analysis of the normal modes of TS1 and TS2 imaginary frequencies $\left(-1500.97\right.$ and $-1533.54 \mathrm{~cm}^{-1}$, respectively) revealed the displacements of N4-H5 and C1-H6 bond lengths of I and INTER, in two 1,2-hydrogen shifts, to produce an $\mathrm{sp}^{3}$-type intermediate [17] and II. (See Table S9 in the Supplementary Information Section). The activation energies for this 1,2-proton shift tautomerization reaction obtained by all elected levels of theory are comparable, with a mean value of $c a .48 .67 \mathrm{kcal} / \mathrm{mol}$. These barrier heights are in good agreement when compared with an activation energy of $57.09 \mathrm{kcal} / \mathrm{mol}$ calculated for 1,2-proton shift for an $\mathrm{H} 9$ to H7-purine tautomerization using MP2/6-31+G* level of theory [17].

It is worth noting that these activation barriers are related to gas-phase conditions, and they are somewhat higher than the solution values obtained from placing 4-methylimidazole between ammonia and ammonium ion. The latter system is used as a model for triggering and facilitation of the proton relay mechanism for the H2-histamine receptor [23]. Our relatively high gas-phase 1,2-proton transfer activation energies mean that the interconversion between I and II could only occur under high thermal conditions. 
Table 5. Zero-point electronic energies (a.u.) and activation energies (kcal/mol) of the tautomerization of imidazole-4-acetic acid (I) and imidazole-5-acetic acid (II) through two transition states (TS1 and TS2) and an intermediate (INTER) using B3LYP, CAM-B3LYP, and $\omega B$ 97XD functionals with $6-311++\mathrm{G}^{* *}$ and aug-cc-pvdz basis sets.

\begin{tabular}{ccccccc}
\hline Level of Theory & Parameter & I & TS1 & INTER & TS2 & II \\
\hline \multirow{2}{*}{ B3LYP/6-311++G** } & Total energy & -454.132 & -454.055 & -454.106 & -454.050 & -454.131 \\
& Act. energy & 48.30 & - & -31.99 & - & 50.80 \\
\hline \multirow{2}{*}{ CAM-B3LYP/6-311++G** } & Total energy & -453.931 & -453.852 & -453.903 & -453.846 & -453.930 \\
& Act. energy & 49.55 & - & -31.99 & - & 52.69 \\
\hline \multirow{2}{*}{$\omega B$ B97XD/6-311++G** } & Total energy & -453.978 & -453.901 & -453.950 & -453.895 & -453.977 \\
& Act. energy & 48.30 & - & -30.73 & - & 51.43 \\
\hline \multirow{2}{*}{ B3LYP/aug-cc-pvdz } & Total energy & -454.065 & -453.989 & -454.039 & -453.984 & -454.063 \\
& Act. energy & 47.67 & - & -31.36 & - & 49.55 \\
\hline \multirow{2}{*}{ CAM-B3LYP/aug-cc-pvdz } & Total energy & -453.863 & -453.785 & -453.835 & -453.779 & -453.861 \\
& Act. energy & 49.92 & - & -31.36 & - & 51.43 \\
\hline \multirow{2}{*}{$\omega B$ B97XD/aug-cc-pvdz } & Total energy & -453.918 & -453.841 & -453.890 & -453.836 & -453.916 \\
& Act. energy & 48.30 & - & 30.73 & - & 50.18 \\
\hline
\end{tabular}

Table 6 lists the gas-phase zero-point electronic and activation energies of the water-assisted 1,3-proton shift for the I↔II tautomerization reaction (See Figure S1 in the Supplementary Information Section) using the elected levels of theory. The barrier heights for this 1,3-hydrogen transfer range between 15.060-19.453 kcal/mol. In Table 6 are, also, logged the zero-point electronic and activation energies of the 1,3-proton shift tautomerization using a first solvation layer of three water molecules. This environment has been simulated by using the PCM solvation model [24] with the CAM-B3LYP and $\omega$ B97XD functionals at $6-311++\mathrm{G}^{* *}$ and aug-cc-pvdz basis sets. The barrier height decreased further to $c a .11 .713 \mathrm{kcal} / \mathrm{mol}$. These results indicate that the gas- or solution-phase I $\leftrightarrow$ II tautomerization of imidazoleacetic acid are feasible at room temperature when assisted by water molecules.

Table 6. Zero-point electronic energies (a.u.) and forward (Ea/f) and backward (Ea/b) activation energies $(\mathrm{kcal} / \mathrm{mol})$ of the gas- and solution-phase water-assisted tautomerization of imidazole-4-acetic acid (I) and imidazole-5-acetic acid (II) through the transition state (TS) using the elected levels of theory.

\begin{tabular}{|c|c|c|c|c|c|c|c|}
\hline \multicolumn{2}{|c|}{ Medium } & Level of Theory & $\mathbf{I}$ & TS & II & $E \mathbf{a} / \mathbf{f}$ & $E \mathbf{a} / \mathbf{b}$ \\
\hline \multirow{9}{*}{$\begin{array}{c}\text { Substrate I } \\
\text { or II + } \\
3 \mathrm{H}_{2} \mathrm{O}\end{array}$} & \multirow{6}{*}{ gas } & B3LYP / 6-311++G & -683.650 & -683.619 & -683.648 & 19.453 & 18.198 \\
\hline & & $\begin{array}{l}\text { CAM-B3LYP/ } \\
6-311++G^{* *}\end{array}$ & -683.369 & -683.341 & -683.368 & 17.570 & 16.943 \\
\hline & & B3LYP/aug-cc-pvdz & -683.536 & -683.505 & -683.534 & 19.453 & 18.198 \\
\hline & & $\begin{array}{l}\text { CAM-B3LYP/ } \\
\text { aug-cc-pvdz }\end{array}$ & -683.255 & -683.226 & -683.253 & 18.198 & 16.943 \\
\hline & & $\omega B 97 X D / 6-311++G^{* *}$ & -683.318 & -683.293 & -683.317 & 15.876 & 15.047 \\
\hline & & $\omega B 97 X D /$ aug-cc-pvdz & -683.421 & -683.396 & -683.420 & 15.938 & 14.997 \\
\hline & \multirow{3}{*}{ solution } & CAM-B3LYP/ & -683.382 & -683.359 & -683.389 & 14.433 & 18.825 \\
\hline & & $\omega B 97 X D / 6-311++G^{* *}$ & -683.337 & -683.312 & -683.331 & 15.835 & 12.093 \\
\hline & & $\omega B 97 X D /$ aug-cc-pvdz & -683.441 & -683.416 & -683.435 & 15.685 & 11.713 \\
\hline
\end{tabular}

On the one hand, when increasing the basis set from $6-311++\mathrm{G}^{* *}$ to aug-cc-pvdz the barrier heights decreased by $0.63 \mathrm{kcal} / \mathrm{mol}$ for B3LYP, increased by $0.37 \mathrm{kcal} / \mathrm{mol}$ for CAM-B3LYP but remained constant for $\omega B$ 97XD functional. On the other hand, the long-range correction elevated the barrier height by 1.25 and $2.25 \mathrm{kcal} / \mathrm{mol}$ when using $6-311++\mathrm{G}^{* *}$ and aug-cc-pvdz basis sets, respectively. This means that the barrier height for imidazoleacetic acid tautomerization is both basis set and DFT functional dependent, but the effect is more conspicuous for the former. 


\subsection{Natural Bond Orbital (NBO) Analysis}

Figure 4 displays the natural atomic charges of I, TS1, INTER, TS2, and II which have been estimated by using B3LYP/6-311++ $\mathrm{G}^{* *}$ level of theory. For I, the imidazole ring two nitrogen atoms $\mathrm{N} 4$ and N8 carried negative charges of $-0.563 \mathrm{e},-0.530 \mathrm{e}$, respectively; while the carbon atom $\mathrm{C} 1$ and the future migrating hydrogen atom $\mathrm{H} 6$ acquired positive charges of $0.230 \mathrm{e}$ and $0.414 \mathrm{e}$, respectively. In TS1, the natural atomic charges of the two nitrogen atoms $(-0.540 \mathrm{e},-0.472 \mathrm{e})$ and the departing proton $(0.384 \mathrm{e})$ diminished a little bit; whilst that of $\mathrm{C} 1$ became almost neutral $(0.053 \mathrm{e})$. When $\mathrm{H} 6$ attached to $\mathrm{C} 1$ in the INTER, the natural atomic charges of N4, N8, C1, and H6 acquired the charges: $-0.497 \mathrm{e},-0.381 \mathrm{e},-0.062 \mathrm{e}$, and $+0.234 \mathrm{e}$, respectively. In TS2 and II, the natural atomic charges of the aforementioned atoms are almost similar to those of TS1 and I, respectively.

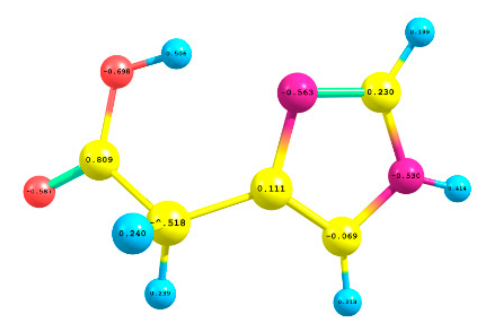

(a)

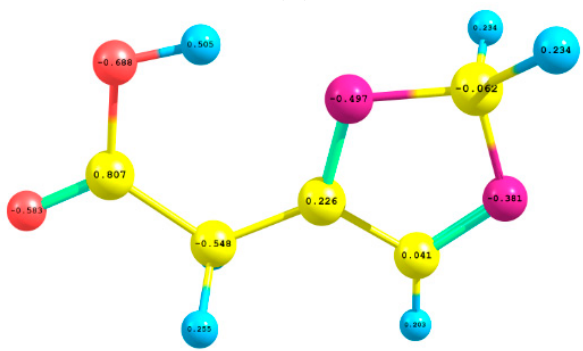

(c)

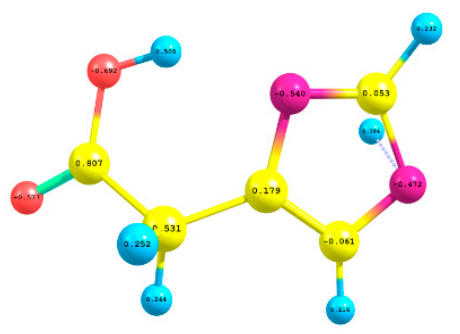

(b)

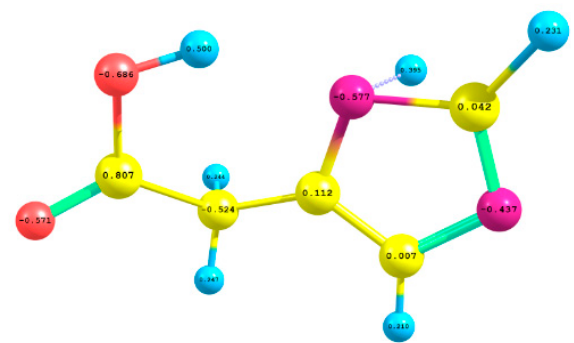

(d)

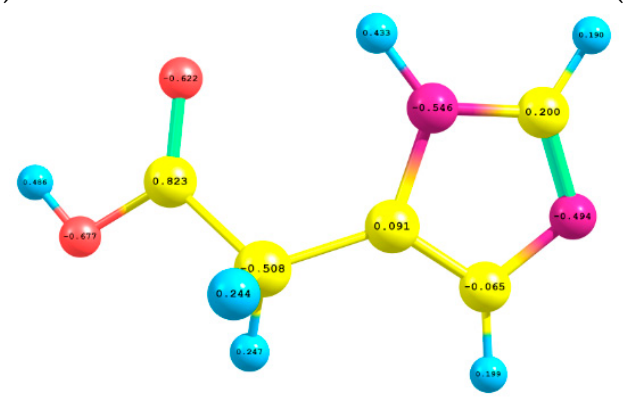

(e)

Figure 4. The natural atomic charges of (a) (I); (b) (TS1); (c) INTER; (d) TS2; and (e) II which were calculated using B3LYP/6-311++ $\mathrm{G}^{* *}$ level of theory.

Table 7 transcribes the second-order perturbation $\left(E_{(2)}\right)$ computation of the hyperconjugative and hydrogen bonding energies of I, TS1, INTER, TS2, and II which have been calculated using B3LYP / 6-311++G** level of theory. The application of Natural Bond Orbital (NBO) theory $[25,26]$ facilitated the analysis of hydrogen bonding [27] and hyperconjugative [28] influences through using the second-order perturbation $\left(E_{(2)}\right)$ given by:

$$
E_{(2)}=\Delta E_{\mathrm{ij}}=q_{\mathrm{i}}\left(F_{\mathrm{ij}}\right)^{2} / \Delta \varepsilon
$$

where $q_{\mathrm{i}}$ denotes the occupancy of the donor orbital, $\mathrm{F}_{\mathrm{ij}}$ estimates the off-diagonal NBO Kohn-Sham Matrix elements and $\Delta \varepsilon$ computes the difference between the energies of donor and acceptor orbitals 
$\mathrm{i}$ and j, respectively. Referring to Table 7, the most influential delocalizing interactions for I, TS1, INTER, TS2 and II are the N and O atoms lone-pairs as a result of the Lone-pair Effect [29]. On the one hand, the two nitrogen atoms lone pairs contributed totals of 106.67 and $92.74 \mathrm{kcal} / \mathrm{mol}$ for the stabilization of I and II, respectively. The strongest of which are the $\mathrm{n}_{1 \mathrm{~N} 8} \rightarrow \pi^{*} \mathrm{C} 1-\mathrm{N} 4(51.30 \mathrm{kcal} / \mathrm{mol}$ for I and $46.06 \mathrm{kcal} / \mathrm{mol}$ for II) and $\mathrm{n}_{1 \mathrm{~N} 8} \rightarrow \pi^{*} \mathrm{C}_{-}-\mathrm{C} 3(28.50 \mathrm{kcal} / \mathrm{mol}$ for I and $33.99 \mathrm{kcal} / \mathrm{mol}$ for II) interactions. On the other hand, those of the $\mathrm{O}$ atoms donated 102.76 and $100.42 \mathrm{kcal} / \mathrm{mol}$ to the stabilization of I and II, respectively; the most influential of which are the $\mathrm{n}_{2 \mathrm{O} 13} \rightarrow \pi^{*} \mathrm{C} 12-\mathrm{O} 15$ (46.54 kcal/mol for I and $43.65 \mathrm{kcal} / \mathrm{mol}$ for II) and $\mathrm{n}_{2 \mathrm{O} 15} \rightarrow \sigma^{*} \mathrm{C12-O13}(30.65 \mathrm{kcal} / \mathrm{mol}$ for I and $32.22 \mathrm{kcal} / \mathrm{mol}$ for II) interactions. It is clear that the large difference between the $\mathrm{N}$ atoms lone pairs hyperconjugative energies of I and II of $13.93 \mathrm{kcal} / \mathrm{mol}$, in favour of I, originates from the hydrogen bonding interaction $\mathrm{n}_{1 \mathrm{~N} 4} \rightarrow \sigma^{*} \mathrm{O} 13-\mathrm{H} 14$ that avails $15.07 \mathrm{kcal} / \mathrm{mol}$ for the stabilization of I. The other provenance of preference of $\mathrm{I}$ is attributed to the $\pi^{*} \mathrm{C} 1-\mathrm{N} 4 \rightarrow \pi_{\mathrm{C} 2-\mathrm{C} 3}^{*}$ antibonding interaction that highly destabilized II by $84.56 \mathrm{kcal} / \mathrm{mol}$ compared to $46.64 \mathrm{kcal} / \mathrm{mol}$ for I.

There are some vicinal $\mathrm{C} 1 \mathrm{~N} 4-\mathrm{C} 2 \mathrm{C}^{*}$ and $\mathrm{C} 2 \mathrm{C} 3-\mathrm{C} 1 \mathrm{~N} 4^{*} \pi$-interactions that contributed also to the stabilities of I and II [30]. The strong antiperiplanar [29] $\pi_{\mathrm{C} 1-\mathrm{N} 4 \rightarrow \pi^{*} \mathrm{C} 2-\mathrm{C} 3}$ donor-acceptor pair contributed 21.61 and $20.06 \mathrm{kcal} / \mathrm{mol}$ for I and II, respectively; while the less strong synperiplanar [28] $\pi_{\mathrm{C} 2-\mathrm{C} 3} \rightarrow \pi^{*} \mathrm{C} 1-\mathrm{N} 4$ delocalization contributed by 14.95 and $14.80 \mathrm{kcal} / \mathrm{mol}$ for the stabilization of I and II, respectively.

Table 7. Second order perturbation $\left(E_{(2)}\right)$ estimation of the hyperconjugative energies $(\mathrm{kcal} / \mathrm{mol})$ of hydrogen bonded imidazole-4-acetic acid (I), the transition states (TS1 and TS2), the intermediate (INTER) and imidazole-5-acetic acid (II) which were calculated using B3LYP/6-311++G** level of theory.

\begin{tabular}{|c|c|c|c|c|c|c|c|}
\hline Parameter & $\mathbf{I}$ & II & Parameter & INTER & Parameter & TS1 & TS2 \\
\hline$\pi_{\mathrm{C} 1-\mathrm{N} 4} \rightarrow \pi^{*} \mathrm{C} 2-\mathrm{C} 3$ & 21.61 & 20.06 & $\sigma_{\mathrm{C} 1-\mathrm{N} 4} \rightarrow \sigma^{*} \mathrm{C} 3-\mathrm{C} 9$ & 7.81 & $\pi_{\mathrm{C} 1-\mathrm{N} 4} \rightarrow \pi_{\mathrm{C} 2-\mathrm{C} 3}$ & 13.24 & 11.84 \\
\hline$\pi_{\mathrm{C} 2-\mathrm{C} 3} \rightarrow \pi^{*} \mathrm{C} 1-\mathrm{N} 4$ & 14.95 & 14.80 & $\sigma_{\mathrm{C} 1-\mathrm{N} 8} \rightarrow \sigma^{*} \mathrm{C} 2-\mathrm{H} 7$ & 6.12 & $\pi_{\mathrm{C} 2-\mathrm{C} 3} \rightarrow \pi^{*} \mathrm{C} 1-\mathrm{N} 4$ & 9.20 & 10.29 \\
\hline $\mathrm{n}_{1 \mathrm{~N} 4} \rightarrow \sigma^{*} \mathrm{C} 1-\mathrm{N} 8$ & 6.59 & 7.34 & $\pi_{\mathrm{C} 2-\mathrm{N} 8} \rightarrow \pi^{*} \mathrm{C} 3-\mathrm{N} 4$ & 14.42 & $\mathrm{n}_{1 \mathrm{~N} 4} \rightarrow \sigma^{*} \mathrm{C} 1-\mathrm{N} 8$ & 4.57 & 5.01 \\
\hline $\mathrm{n}_{1 \mathrm{~N} 4} \rightarrow \sigma^{*} \mathrm{C} 2-\mathrm{C} 3$ & 5.21 & 4.85 & $\pi_{\mathrm{C} 3-\mathrm{N} 4} \rightarrow \pi^{*} \mathrm{C} 2-\mathrm{N} 8$ & 11.31 & $\mathrm{n}_{2 \mathrm{~N} 4} \rightarrow \pi^{*} \mathrm{C} 1-\mathrm{N} 8$ & 23.01 & 17.54 \\
\hline $\mathrm{n}_{1 \mathrm{~N} 4} \rightarrow \sigma^{*} \mathrm{O} 13-\mathrm{H} 14$ & 15.07 & $<0.5$ & $\sigma_{\mathrm{C} 9-\mathrm{H} 10} \rightarrow \pi^{*} \mathrm{C} 3-\mathrm{N} 4$ & 5.15 & $\mathrm{n}_{2 \mathrm{~N} 4} \rightarrow \pi^{*} \mathrm{C} 2-\mathrm{C} 3$ & 15.68 & 16.12 \\
\hline $\mathrm{n}_{1 \mathrm{~N} 8} \rightarrow \pi^{*} \mathrm{C} 1-\mathrm{N} 4$ & 51.30 & 46.06 & $\sigma_{\mathrm{C} 9-\mathrm{H} 11} \rightarrow \pi_{\mathrm{C} 3}^{*} \mathrm{~N} 4$ & 5.15 & $\mathrm{n}_{1 \mathrm{~N} 8} \rightarrow \sigma^{*} \mathrm{C} 1-\mathrm{N} 4$ & 3.84 & 4.47 \\
\hline $\mathrm{n}_{1 \mathrm{~N} 8} \rightarrow \pi_{\mathrm{C} 2-\mathrm{C} 3}^{*}$ & 28.50 & 33.99 & $\sigma_{\mathrm{O} 13-\mathrm{H} 14} \rightarrow \sigma^{*} \mathrm{C} 12-\mathrm{O} 15$ & 55.48 & $\mathrm{n}_{1 \mathrm{O} 13} \rightarrow \sigma^{*} \mathrm{C} 9-\mathrm{C} 12$ & 3.01 & 2.89 \\
\hline $\mathrm{n}_{2 \mathrm{O} 13} \rightarrow \pi^{*} \mathrm{C} 12-\mathrm{O} 15$ & 46.54 & 43.64 & $\mathrm{n}_{1 \mathrm{~N} 4} \rightarrow \sigma_{\mathrm{C} 2-\mathrm{C} 3}^{*}$ & 7.68 & $\mathrm{n}_{2 \mathrm{O} 13} \rightarrow \pi^{*} \mathrm{C} 12-\mathrm{O} 15$ & 23.16 & 22.32 \\
\hline $\mathrm{n}_{2 \mathrm{O} 13} \rightarrow \sigma^{*} \mathrm{C} 9-\mathrm{C} 12$ & 5.92 & $<0.5$ & $\mathrm{n}_{1 \mathrm{~N} 4} \rightarrow \sigma^{*} \mathrm{O} 13-\mathrm{H} 14$ & 18.96 & $\mathrm{n}_{2 \mathrm{O} 15} \rightarrow \sigma^{*} \mathrm{C} 9-\mathrm{C} 12$ & 10.07 & 9.98 \\
\hline $\mathrm{n}_{2 \mathrm{O} 15} \rightarrow \sigma^{*} \mathrm{C} 9-\mathrm{C} 12$ & 19.65 & 17.55 & $\mathrm{n}_{1 \mathrm{~N} 8} \rightarrow \sigma^{*} \mathrm{C} 1-\mathrm{N} 4$ & 5.07 & $\mathrm{n}_{2 \mathrm{O} 15} \rightarrow \sigma^{*} \mathrm{C} 12-\mathrm{O} 13$ & 15.33 & 15.76 \\
\hline $\mathrm{n}_{2 \mathrm{O} 15} \rightarrow \sigma^{*} \mathrm{C} 12-\mathrm{O} 13$ & 30.65 & 32.22 & $\mathrm{n}_{1 \mathrm{~N} 8} \rightarrow \sigma^{*} \mathrm{C} 2-\mathrm{C} 3$ & 7.39 & $\sigma_{\mathrm{C} 1-\mathrm{N} 4} \rightarrow \mathrm{n}^{*} 1 \mathrm{H} 6$ & 31.64 & 15.22 \\
\hline$\pi_{\mathrm{C} 1-\mathrm{N} 4} \rightarrow \mathrm{n}^{*} 1 \mathrm{H} 6$ & $<0.5$ & $<0.5$ & $\mathrm{n}_{1 \mathrm{O} 13} \rightarrow \sigma^{*} \mathrm{C} 9-\mathrm{C} 12$ & 6.43 & $\sigma_{\mathrm{C} 1-\mathrm{H} 5} \rightarrow \mathrm{n}^{*} 1 \mathrm{H} 6$ & 4.75 & 4.46 \\
\hline$\sigma_{\mathrm{C} 1-\mathrm{N} 8} \rightarrow \mathrm{n}^{*}{ }_{1 \mathrm{H} 6}$ & $<0.5$ & $<0.5$ & $\mathrm{n}_{2 \mathrm{O} 13} \rightarrow \pi^{*} \mathrm{C} 12-\mathrm{O} 15$ & 50.42 & $\pi_{\mathrm{C} 1-\mathrm{N} 8} \rightarrow \mathrm{n}^{*} 1 \mathrm{H} 6$ & 15.07 & 30.02 \\
\hline $\mathrm{n}_{1 \mathrm{~N} 8} \rightarrow \mathrm{n}^{*}{ }_{1 \mathrm{H} 6}$ & $<0.5$ & $<0.5$ & $\mathrm{n}_{2 \mathrm{O} 15} \rightarrow \sigma^{*} \mathrm{C} 9-\mathrm{C} 12$ & 20.20 & $\mathrm{n}_{1 \mathrm{~N} 8} \rightarrow \mathrm{n}^{*}{ }_{1 \mathrm{H} 6}$ & 8.97 & 7.78 \\
\hline $\mathrm{n}_{2 \mathrm{~N} 8} \rightarrow \mathrm{n}^{*} 1 \mathrm{H} 6$ & $<0.5$ & $<0.5$ & $\mathrm{n}_{2 \mathrm{O} 15} \rightarrow \sigma^{*} \mathrm{C} 12-\mathrm{O} 13$ & 30.19 & $\mathrm{n}_{2 \mathrm{~N} 8} \rightarrow \mathrm{n}^{*} 1 \mathrm{H} 6$ & 129.64 & 127.67 \\
\hline Total & 247.99 & 223.51 & Total & 201.78 & Total & 311.18 & 301.28 \\
\hline$\pi^{*} \mathrm{C} 1-\mathrm{N} 4 \rightarrow \pi^{*} \mathrm{C} 2-\mathrm{C} 3$ & 46.64 & 84.56 & - & - & $\mathrm{n}^{*}{ }_{1 \mathrm{H} 6} \rightarrow \pi^{*} \mathrm{C} 1-\mathrm{N} 4$ & 730.01 & 347.08 \\
\hline
\end{tabular}

The contribution of the aforementioned interactions to the stabilities of TS1 and TS2 diminished, paving the way for the ones between the imidazole ring atoms (N4, N8 and $\mathrm{C} 1)$ and the migrating $\mathrm{H} 6$ atom. These delocalizations $\left(\pi_{\mathrm{C} 1-\mathrm{N} 4} \rightarrow \mathrm{n}^{*}{ }_{1 \mathrm{H} 6}, \sigma_{\mathrm{C} 1-\mathrm{H} 5} \rightarrow \mathrm{n}^{*}{ }_{1 \mathrm{H} 6}, \sigma_{\mathrm{C} 1-\mathrm{N} 8} \rightarrow \mathrm{n}^{*}{ }_{1 \mathrm{H} 6}, \mathrm{n}_{1 \mathrm{~N} 8} \rightarrow \mathrm{n}^{*}{ }_{1 \mathrm{H} 6}\right.$ and $\left.\mathrm{n}_{2 \mathrm{~N} 8} \rightarrow \mathrm{n}^{*} 1 \mathrm{H} 6\right)$ yielded totals of 190.07 and $185.15 \mathrm{kcal} / \mathrm{mol}$ for their stabilities, respectively. These very high charge transfer interactions led to the debilitation of the N4-H6 and C1-H6 bonds and hence facilitated the transport of the proton from N4 to $\mathrm{C} 1$ and finally to N8 atom. These two 1,2-hydrogen shifts [17] produced an $\mathrm{sp}^{3}$-type intermediate (INTER) in the first step and II in the second jump.

Unlike I and II, the most influential hyperconjugative interactions in the INTER include $\sigma \rightarrow \sigma^{*}$ charge transfers that contributed a total of $29.71 \mathrm{kcal} / \mathrm{mol}$ to its stability. The $\mathrm{n} \rightarrow \sigma^{*}$ or $\mathrm{n} \rightarrow \pi^{*}$ delocalizations contributed $146.34 \mathrm{kcal} / \mathrm{mol}$ for the stability of the INTER; compared to 209.43 and 
$186.65 \mathrm{kcal} / \mathrm{mol}$ for I and II, respectively. This could lead, safely, to the conclusion that the INTER is less stable than both I and II. The instabilities of TS1 and TS2 relative to I, II and INTER are estimated by 730.01 and $347.08 \mathrm{kcal} / \mathrm{mol}$, respectively, due to the $\mathrm{n}^{*} 1 \mathrm{H}_{6} \rightarrow \pi^{*} \mathrm{C} 1-\mathrm{N} 4$ antibonding interaction.

All our elected levels of theory predicted relative stabilities of I and II in favor of the former by $c a .0 .750-0.877 \mathrm{kcal} / \mathrm{mol}$, which is below the chemical accuracy limit of $1.000 \mathrm{kcal} / \mathrm{mol}$ [13]. This fact necessitated the use of a more rigorous approach that applies the steric, electrostatic, or hyperconjugative interactions [30] for the assurance of these relative stabilities. The relative impacts of these three factors on the relative stabilities of I and II were resolved by using NBO computations applying the \$DEL Keylist of the NBO version 3.1 [31] integrated within the Gaussian09 Suite [32]. The results comprising the total $\mathrm{SCF}$, deletion and hyperconjugative energies of I and II using B3LYP /6-311++G** level of theory are shown in Table 8. The total SCF energy is indicative of the combined action of the three factors; where I is supported over II by $1.254 \mathrm{kcal} / \mathrm{mol}$. The energy of deletion predicts the Lewis Structures of I and II where only the steric and electrostatic factors prevail. On the one hand, the Lewis Structures showed the preference of II over I by a huge amount of energy of $2068.542 \mathrm{kcal} / \mathrm{mol}$ as a result of minimal steric hindrance and smaller electrostatic repulsion in II compared to their effect in I. This is manifested by the crowdedness imposed by the closing up of the N4C3C9 angle in I $\left(120.6^{\circ}\right.$ ), compared to $123.9^{\circ}$ in II (See Table S4), which shortened the distance between N4 and H14 (1.832 ̊) in I, compared to $2.255 \AA$ between O15 and H6 in II. These situations brought about the formation of the hydrogen bonding in I. On the other hand, the delocalization interactions were competitive enough to avail $2069.796 \mathrm{kcal} / \mathrm{mol}$ for stabilization of I over II. That is, it exceeded the steric hindrance and the electrostatic repulsion energies of I by $1.254 \mathrm{kcal} / \mathrm{mol}$. In the end, we can safely conclude that the preference of I over II is mainly due to hyperconjugation; or in particular to hydrogen bonding.

Table 8. NBO analyses of the total SCF, deletion and delocalization energies (a.u.) for hydrogen bonded imidazole-4-acetic acid (I) and imidazole-5-acetic acid (II) which were calculated by using B3LYP functional with 6-311++ $\mathrm{G}^{* *}$ basis set.

\begin{tabular}{cccc}
\hline Parameter & I & II & $\Delta \boldsymbol{E}^{\mathbf{a}}$ \\
\hline Energy of Deletion (L) & -447.599 & -450.897 & +2068.542 \\
Total SCF Energy (full) & -454.247 & -454.245 & -1.254 \\
Delocalization & -6.648 & -3.348 & -2069.796 \\
Energy(NL) & & & \\
\hline \multicolumn{4}{c}{$\Delta E=E_{\mathrm{I}}-E_{\text {II }} \mathrm{kcal} / \mathrm{mol}}$.
\end{tabular}

\subsection{Nonlinear Optical (NLO) Properties}

In Table 9 are shown the nonlinear optical (NLO) properties of I and II which have been computed by applying B3LYP, CAM-B3LYP, and $\omega$ B97XD functionals with $6-311++G^{* *}$ and aug-cc-pvdz basis sets. We recorded the hyperpolarizabilities in atomic units (a.u.) which are equated to electrostatic units (esu) through the conversion factor: 1 a.u. $=8.6393 \times 10^{-33} \mathrm{esu}$. The total hyperpolarizabilities $\left(\beta_{\text {tot }}\right)$ are given by the equation:

$$
\beta_{\text {tot }}=\left[\beta_{x}^{2}+\beta_{y}^{2}+\beta_{z}^{2}\right]^{1 / 2}
$$

where

$$
\beta_{\mathrm{i}}=\beta_{\mathrm{iii}}+{ }^{1} / 3 \sum\left(\beta_{\mathrm{ijj}}+\beta_{\mathrm{jij}}+\beta_{\mathrm{jij}}\right)
$$

In Table 9 are also listed the dipole moments $(\mu)$, the frontier orbitals (HOMOs and LUMOs) energies and the energy gaps (E.G.) of I and II, which were obtained by using the elected levels of theory. Some experimental [33] and theoretical [34] hyperpolarizability values for the prototypical NLO compound, p-nitro-aniline (pNA), are also given for the purpose of comparison. The dipole 
moments of I were predicted by all levels of theory to be more than double those of II. It is interesting to note that the inclusion of the long-range correction on the traditional hybrid functional [19] has increased the dipole moments by $2 \%-3 \%$ [35]; meanwhile the implication of the dispersion correction [20] has decreased them by almost the same amount. It is worth emphasizing that the changes of dipole moments are method rather than basis set dependent as the latter altered them by less than $1 \%$. In addition, aug-cc-pvdz basis set yielded lower dipole moment values compared to $6-311++G^{* *}$.

Table 9. Dipole moments ( $\mu$ /Debye), Highest Occupied Molecular Orbital (HOMO) and Lowest Unoccupied Molecular Orbital (LUMO) energies $(\mathrm{eV})$ and their energy gaps (E.G. $=\Delta E / \mathrm{eV}$ ), and total hyperpolarizability ( $\beta_{\text {tot }} /$ a.u.) for I and II which were computed using B3LYP, CAM-B3LYP, and $\omega B$ 97XD functionals with 6-311++ $\mathrm{G}^{* *}$ and aug-cc-pvdz basis sets. The data for p-nitroaniline (pNA) is given for comparison purposes.

\begin{tabular}{|c|c|c|c|c|}
\hline Level of Theory & Parameter & $\mathbf{I}$ & II & $\mathrm{pNA}^{\mathrm{a}}$ \\
\hline \multirow{5}{*}{ B3LYP / 6311++G* } & $\mu$ & 8.59 & 3.92 & 7.16 \\
\hline & HOMO & -6.92 & -6.40 & - \\
\hline & LUMO & -0.88 & -0.92 & - \\
\hline & $\Delta E$ & 6.04 & 5.48 & 4.29 \\
\hline & $\beta_{\text {tot }}$ & 223 & 65 & 1327 \\
\hline \multirow{5}{*}{ CAM-B3LYP/6-311++G** } & $\mu$ & 8.79 & 4.04 & 7.23 \\
\hline & HOMO & -8.47 & -7.88 & - \\
\hline & LUMO & -0.20 & 0.07 & - \\
\hline & $\Delta E$ & 8.27 & 7.95 & 6.78 \\
\hline & $\beta_{\text {tot }}$ & 143 & 19 & 1350 \\
\hline \multirow{5}{*}{$\omega B 97 X D / 6-311++G^{* *}$} & $\mu$ & 8.59 & 4.04 & 7.16 \\
\hline & HOMO & -8.94 & -8.40 & - \\
\hline & LUMO & 0.58 & 0.87 & - \\
\hline & $\Delta E$ & 9.52 & 9.27 & 7.96 \\
\hline & $\beta_{\text {tot }}$ & 143 & 32 & 1350 \\
\hline \multirow{5}{*}{ B3LYP/aug-cc-pvdz } & $\mu$ & 8.52 & 3.88 & - \\
\hline & $\mathrm{HOMO}$ & -6.88 & -6.35 & - \\
\hline & LUMO & -0.91 & -0.93 & - \\
\hline & $\Delta E$ & 5.97 & 5.42 & - \\
\hline & $\beta_{\text {tot }}$ & 229 & 45 & - \\
\hline \multirow{5}{*}{ CAM-B3LYP/aug-cc-pvdz } & $\mu$ & 8.71 & 4.01 & - \\
\hline & HOMO & -8.42 & -7.82 & - \\
\hline & LUMO & -0.26 & 0.00 & - \\
\hline & $\Delta E$ & 8.16 & 7.82 & - \\
\hline & $\beta_{\text {tot }}$ & 143 & 36 & - \\
\hline \multirow{5}{*}{$\omega B 97 X D / a u g-c c-p v d z$} & $\mu$ & 8.54 & 3.99 & - \\
\hline & HOMO & -8.90 & -8.34 & - \\
\hline & LUMO & 0.45 & 0.74 & - \\
\hline & $\Delta E$ & 9.35 & 9.08 & - \\
\hline & $\beta_{\text {tot }}$ & 152 & 53 & - \\
\hline Expt $^{b}$ & $\beta_{\Pi}(-2 \omega ; \omega ; \omega)$ & - & - & $1072 \pm 44$ \\
\hline
\end{tabular}

All tested levels of theory computed higher HOMO-LUMO energy gaps (E.G.) for I compared to II. Among the elected functionals, the traditional hybrid B3LYP method gave lower values compared to those estimated by the LC-DFT functionals (CAM-B3LYP and $\omega B$ 97XD). That is, the effect of the long-range correction [19], has increased the E.G. by ca. 37\% regardless of the basis set used; whilst the inclusion of dispersion correction [20] further widened them by $c a .15 \%$ independent of the applied basis set. Again, the basis set effect is minimal compared to that of the functionals. Figures 5 and 6 depict the frontier molecular orbitals (FMOs) of I and II which have been pictured using B3LYP / 6-311++G** level of theory. The HOMOs for both tautomers are delocalized mainly over the imidazole ring as $\pi(\mathrm{C}=\mathrm{N})$ and $\pi(\mathrm{C}=\mathrm{C})$ bonding orbitals, as well as oxygen atom lone pairs. The LUMO for I exits in the form of $\sigma_{\mathrm{p}}(\mathrm{C}-\mathrm{N}$ and $\mathrm{C}-\mathrm{C})$ antibonding and nitrogen atom lone pair orbitals; 
while it occurs as $\pi$-antibonding orbitals over the acetate moiety for II. The strongly stabilizing H-bonding phenomenon that existed only for I is shown in Figure 7.

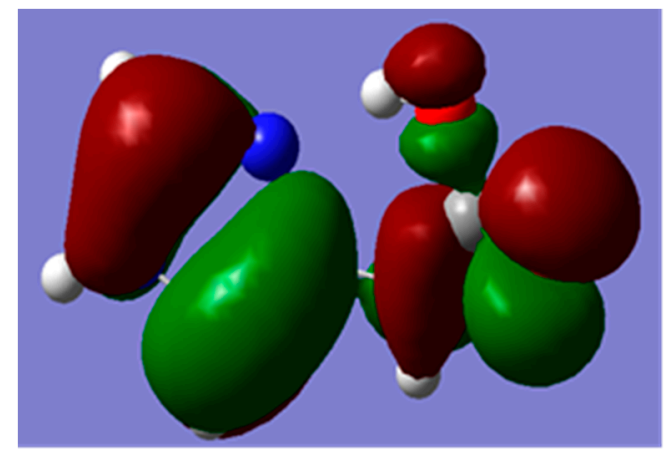

(a)

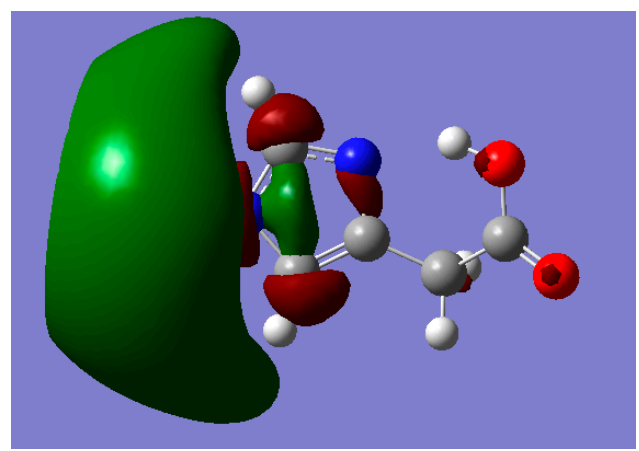

(b)

Figure 5. MOs of Hydrogen Bonded Imidazole-4-acetic acid (I) which were calculated by using B3LYP/6-311++G* level of theory. (a) HOMO; (b) LUMO. Note: carbon, oxygen, nitrogen and hydrogen atoms are in grey, red, blue and white colours, respectively.

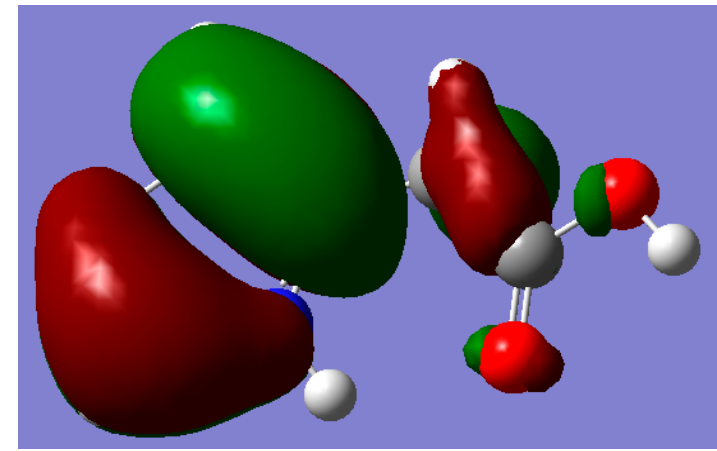

(a)

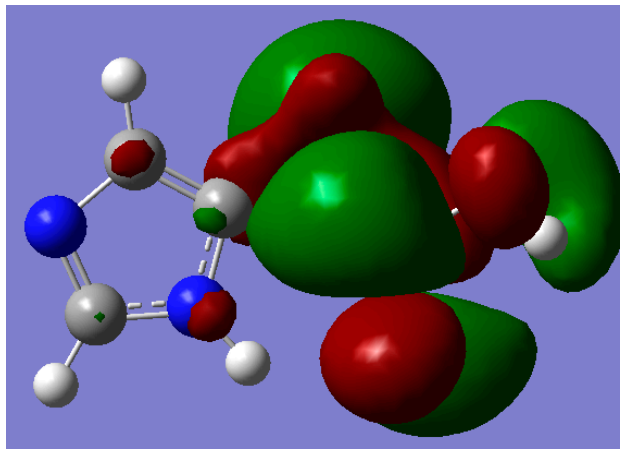

(b)

Figure 6. MOs of Hydrogen Bonded Imidazole-5-acetic acid (II) which were calculated by using B3LYP/6-311++G** level of theory. (a) HOMO; (b) LUMO. Note: carbon, oxygen, nitrogen and hydrogen atoms are in grey, red, blue and white colours, respectively.

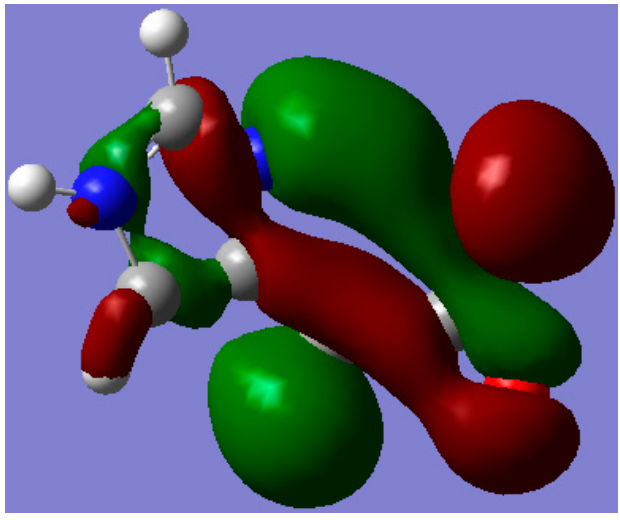

(a)

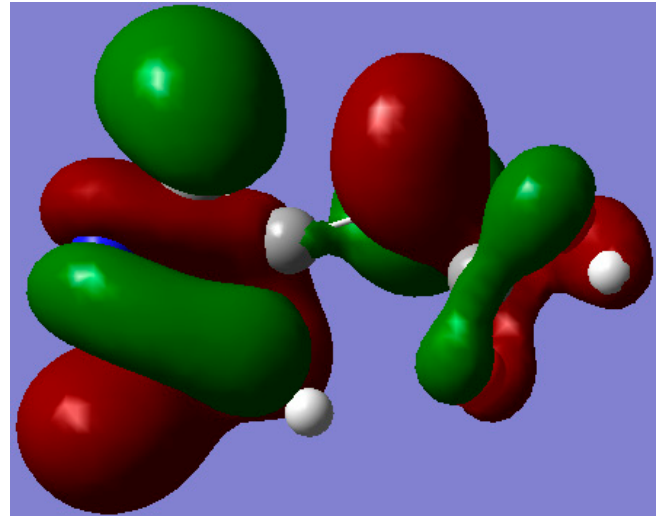

(b)

Figure 7. The pictorial visualization of HOMO-5 showing the Hydrogen bonding between the lone pair of the trigonal nitrogen atom of the imidazole ring in (a) (I) and its absence in (b) (II). Note: carbon, oxygen, nitrogen and hydrogen atoms are in grey, red, blue and white colours, respectively. 
As displayed by Figure 8, the destabilization of the HOMOs and the stabilization of the LUMOs by the traditional hybrid functional (B3LYP) have led to lower E.G. The inclusion of the long-range and dispersion corrections (CAM-B3LYP and $\omega$ B97XD functionals) have progressively stabilized the HOMOs and destabilized the LUMOs. The net effect yielded higher E.G. that follows the sequence: $\omega B$ B7XD > CAM-B3LYP > B3LYP. The $6-311++G^{* *}$ basis set computed a little bit higher E.G. in comparison to those obtained from aug-cc-pvdz. These findings are in excellent agreement with previous literature investigations [36-38].

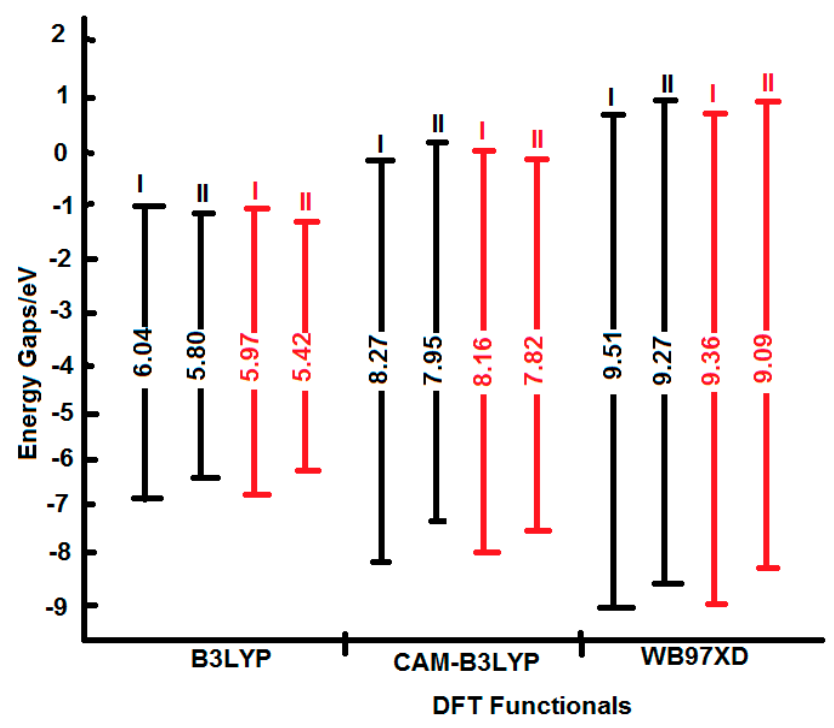

Figure 8. Schematic molecular orbital energy level diagrams of I and II tautomers which have been calculated using B3LYP, CAM-B3LYP, and xB97XD functionals with 6-311++G** (black lines) and aug-cc-pvdz (red lines) basis sets.

The total hyperpolarizabilities $\left(\beta_{\text {tot }}\right)$ of the two tautomers estimated by using B3LYP, CAM-B3LYP, and $\omega B$ B7XD functionals with $6-311++G^{* *}$ and aug-cc-pvdz basis sets are listed in Table 8. The $\beta_{\text {tot }}$ values obtained from the traditional hybrid functional (B3LYP) are usually overestimated compared to those computed by LC-DFT functionals (CAM-B3LYP and $\omega B$ B97XD) [39]. Apart from the value obtained for II using B3LYP/aug-cc-pvdz level of theory, this trend is met by the other values that can hardly show any dispersion correction effect [36]. This discrepancy could be due to the small $\beta_{\text {tot }}$ values computed for II, which could probably encounter high percentage error. It is of interest to mention that the total hyperpolarizabilities of I are 3-5-fold higher than those of II. It is quite safe to conclude that the $\beta_{\text {tot }}$ values are basis-set independent. The existence of $\mathrm{H}$-bonding charge transfer in I could probably be responsible for the relatively enhanced values. This is exemplified by the $\mathrm{n}_{\mathrm{N} 4} \rightarrow \sigma^{*} \mathrm{O} 13-\mathrm{H} 14$ interaction that contributed $15.07 \mathrm{kcal} / \mathrm{mol}$ for the stabilization of I. However, compared to experimental [33] and theoretical [34] hyperpolarizabilities of pNA, all our calculated $\beta_{\text {tot }}$ values are extremely small. As such, the imidazoleacetic acid molecule would not show any NLO properties. We judge this by: (1) the tetrahedral carbon atom that denied co-planarity between the imidazole ring and the acetate group; and (2) the absence of an electron-donating group for a perfect push-pull $\pi$-conjugated system [38]. Therefore, its NLO characters could probably be tailored and enormously enhanced by attaching an amino group, as an electron-donating entity, opposite to the electron-withdrawing acetate moiety.

Table 9 also lists the energy gaps (E.G.) for the two tautomers. A number of theoretical [40,41] and experimental [42] studies establish an inverse relation between the total hyperpolarizabilities and the HOMO-LUMO energy gaps. This criterion facilitates the eventuality of charge transfer that leads to higher hyperpolarizability. Our studied systems violate this relation. This is because the enhanced hyperpolarizabilities are dictated by many other factors. They include, in addition 
to small HOMO-LUMO energy gaps, planarity, large dipole moments, and presence of H-bonding and a push-pull mechanism. Both I and II are non-planar and devoid of a $\pi$-conjugated push-pull system. It is obvious that I has larger HOMO-LUMO energy gaps, compared to II; nonetheless, it gave relatively higher hyperpolarizabilities. This is, probably, because it has higher dipole moments as well as acquiring an $\mathrm{H}$-bonding character.

\section{Computational Details}

The standard Gaussian09 programs [32] were used to carry out all calculations. The geometries of H-bonded imidazole-4-acetic acid (I) and imidazole-5-acetic acid (II) were fully optimized using density functional theory (DFT). The traditional hybrid exchange-correlation Becke, three-parameter, Lee-Yang-Parr (B3LYP [43,44]) the long-range corrected (LC-DFT) column-attenuating method (CAM-B3LYP [19]) and the LC-DFT with dispersion corrections, wB97XD [20], functionals with the triple-zeta with polarization and diffuse functions on the hydrogen and heavy atoms basis set, 6-311++ $G^{* *}[45]$, and the augmented correlation-consistent polarized valence double-zeta, aug-cc-pvdz [46] basis sets were applied. The transition states (TS1 and TS2) of the interconversion between I and II was requested with the Berry Keyword [47] using B3LYP/6-311++ $G^{* *}$ level of theory. The Intrinsic Reaction Coordinate (IRC) [48] of the interconversion was monitored for the TSs that connected the minima in the potential energy profiles of I and II. The imaginary frequency designating the TSs and the IRC were investigated using GaussView [49] and Chemcraft [50] softwares.

The electric charges and hyperconjugative energies of I, TS1, INTER, TS2, and II were estimated using Version 3.1 of natural bond orbital (NBO) program [31] with the elected levels of theory. The idea here is to estimate the relative stabilities of the substrates using the donor-acceptor approach.

\section{Conclusions}

The gas-phase thermal tautomerization reaction between imidazole-4-acetic (I) and imidazole-5-acetic acid (II) was investigated theoretically and computationally using density functional theory (DFT). The traditional hybrid functional (B3LYP) and the long-range and dispersion corrected functionals (CAM-B3LYP and $\omega$ B97XD) were applied. The basis sets tested were $6-311++G^{* *}$ and aug-cc-pvdz. The geometrical parameters obtained for the two tautomers are comparable and agree satisfactorily with experimental ones [12]. The hybrid functional (B3LYP) estimated longer bond lengths compared to the LC-DFT functionals (CAM-B3LYP and $\omega B$ 97XD); while the $6-311++G^{* *}$ basis set gave longer bond lengths compared to those obtained from aug-cc-pvdz basis set. All tested levels of theory favor I over II by $0.750-0.877 \mathrm{kcal} / \mathrm{mol}$. The inclusion of the long-range and dispersion corrections affects $\Delta E, \Delta G$, and $K$. The gas-phase tautomerization reaction between I and II adopted a 1,2-proton shift mechanism, involving two transition states, with activation energies between 47.67 and $52.69 \mathrm{kcal} / \mathrm{mol}$ and an $\mathrm{sp}^{3}$-type intermediate. These data indicate that the interconversion between I and II, in the gas-phase, could only take place under severe thermal conditions.

Both I and II are characterized by high hyperconjugative interactions. The $\mathrm{N}$ and $\mathrm{O}$ atoms lone-pairs interactions with the imidazole ring and acetate group bonds contribute immensely to the stabilization of both tautomers. The origin of preference of I over II is attributed to the hydrogen bonding interaction: $\mathrm{n}_{\mathrm{N} 4} \rightarrow \sigma^{*} \mathrm{O} 13-\mathrm{H} 14$ that contributed $15.07 \mathrm{kcal} / \mathrm{mol}$.

The total hyperpolarizability values of I are 3-5-fold greater than those for II despite the fact that the HOMO-LUMO energy gaps (E.G.) of the latter are smaller. This finding violates the inverse relation between total hyperpolarizability and E.G. values. This hurdle was overcome by the existence of H-bonding and higher dipole moments. The long-range correction is quite essential for total hyperpolarizability DFT evaluation as the traditional hybrid functional overestimate it. Finally, the computation of $\beta_{\text {tot }}$ values is basis set independent. 
Supplementary Materials: Supplementary materials can be found at http://www.mdpi.com/1422-0067/16/ 11/25959/s1.

Acknowledgments: This Project was funded by the Deanship of Scientific Research (DSR) King Abdulaziz University, Jeddah, under Grant No. 110-130-1436-G. The authors, therefore, acknowledge with thanks Deanship of Scientific Research support for Scientific Research.

Author Contributions: Saadullah G. Aziz surveyed the literature for this research project and designed it. Osman I. Osman interpreted data and drafted the paper. Shaaban A. Elroby carried out the calculations and analyzed results. Rifaat $\mathrm{H}$. Hilal critically revised and approved the paper.

Conflicts of Interest: The authors declare no conflict of interest.

\section{References}

1. Hochachka, P.W.; Somero, G.N. Biochemical Adaptation: Mechanisms and Process in Physiological Evolution; Oxford University Press: New York, NY, USA, 2002; pp. 466-467.

2. Schayer, R.W. Catabolism of histamine in vivo. In Handbook of Experimental Pharmacology; Eichler, O., Farah, A., Eds.; Springer-Verlag: Heidelberg, Germany; Berlin, Germany, 1966; Volume XVIII/1, pp. 673-683.

3. Karjala, S.A.; Turnquest, B.W. The characterization of two methylimidazoleacetic acids as radioactive histamine. J. Am. Chem. Soc. 1955, 77, 6358-6359. [CrossRef]

4. Thomas, B.; Prell, G.D. Imidazoleacetic Acid, a $\gamma$-aminobutyric acid receptor agonist, can be formed in rat brain by oxidation of histamine. J. Neurochem. 1995, 65, 818-826. [CrossRef] [PubMed]

5. Mehler, A.H.; Tabor, H.; Bauer, H. The oxidation of histamine to imidazoleacetic acid in vivo. J. Biol. Chem. 1952, 197, 475-480. [PubMed]

6. Tunnicliff, G. Pharmacology and function of imidazole-4-acetic acid in brain. Gen. Pharmacol. 1998, 31, 503-509. [CrossRef]

7. Caliendo, G.; Cirino, G.; Greco, G.; Novellino, E.; Perissutti, E.; Pinto, A.; Santagada, V.; Silipo, C.; Sorrentino, L. Synthesis and structure-activity relationships of antiinflammatory 1-methyl-2-(4-X-benzoyl)imidazole-5-acetic acids. Eur. J. Med. Chem. 1994, 29, 381-388. [CrossRef]

8. Yoshiyasu, F.; Shoji, K.; Kohei, N. Imidazole-5-Acetic Acid Derivatives, Their Production and Use. EP 0028834 A1, 20 May 1981.

9. Torok, I.; Surdy, P.; Rockenbauer, A.; Korecz, L., Jr.; Anthony, G.J.; Koolhaas, A.; Gajda, T. Nickel(II)-, copper(II)- and zinc(II)-complexes of some substituted imidazole ligands. J. Inorg. Biochem. 1998, 71, 7-14. [CrossRef]

10. Drozzdzzewski, P.; Pawlak, B.; Glowiak, T. Crystal structure and spectroscopic properties of aquabis(imidazole-4-acetato)copper(II). J. Coord. Chem. 2002, 55, 735-744. [CrossRef]

11. Kurdziel, K.; Głowiak, T.; Materazzi, S.; Jezierska, J. Crystal structure and physico-chemical properties of cobalt(II) and manganese(II) complexes with imidazole-4-acetate anion. Polyhedron 2003, 22, 3123-3128. [CrossRef]

12. Jones, G.P.; Pauling, P.J. Crystal and molecular structure of imidazole-4-acetic acid hydrochloride. J. Chem. Soc. Perkin II 1976, 34-36. [CrossRef]

13. Lia, G.-S.; Ruiz-Lbpez, M.F.; Zhang, M.-S.; Maigret, B. Ab initio calculations of tautomer equilibrium and protonation enthalpy of 4- and 5-methylimidazole in the gas phase: Basis set and correlation effects. J. Mol. Struct. 1998, 422, 197-204. [CrossRef]

14. Topiol, S.; Weinstein, H.; Osman, R. A Theoretical investigation of histamine tautomerism. J. Med. Chem. 1984, 27, 1531-1533. [CrossRef] [PubMed]

15. Wiberg, K.B. Basis set effects on calculated geometries: 6-311++G** vs. aug-cc-pvdz. J. Comput. Chem. 2004, 25, 1342-1346. [CrossRef] [PubMed]

16. Platts, J.A.; Maarof, H.; Harris, K.D.M.; Lim, G.K.; Willock, D.J. The effect of intermolecular hydrogen bonding on the planarity of amides. Phys. Chem. Chem. Phys. 2012, 14, 11944-11952. [CrossRef] [PubMed]

17. Ahn, D.; Lee, S.; Kim, B. Solvent-mediated tautomerization of purine: Single to quadruple proton transfer. Chem. Phys. Lett. 2004, 390, 384-388.

18. Cho, S.G.; Cheun, Y.G.; Park, B.S. A computational study of imidazole, 4-nitroimidazole, 5-nitroimidazole and 4,5-dinitroimidazole. J. Mol. Struct. 1998, 432, 41-53. [CrossRef] 
19. Yanai, T.; Tew, D.P.; Handy, N.C.A. New hybrid exchange-correlation functional using the Coulomb-attenuating method (CAM-B3LYP). Chem. Phys. Lett. 2004, 393, 51-57.

20. Chai, J.-D.; Head-Gordon, M. Long-range corrected hybrid density functionals with damped atom-atom dispersion corrections. Phys. Chem. Chem. Phys. 2008, 10, 6615-6620. [CrossRef] [PubMed]

21. Worth, G.A.; King, P.M.; Richards, W.G. Histamine tautomerism and its mode of action. Biochim. Biophys. Acta 1989, 993, 134-136. [CrossRef]

22. Jimenez, V.; Alderete, J.B. Complete basis set calculations on the tautomerism and protonation of triazoles and tetrazoles. J. Mol. Struct. 2006, 775, 1-7. [CrossRef]

23. Weinstein, H.; Mazurek, A.P.; Osman, R.; Topiol, S. Theoretical Studies on the activation mechanism of the histamine H2-receptor: The Proton transfer between histamine and a receptor model. Mol. Pharm. 1985, 29, $28-33$.

24. Cances, E.; Mennucci, B.; Tomasi, J. A new integral equation formulism for polarizable continuum model: Theoretical background and applications to isotropic and anisotropic dielectrics. J. Chem. Phys. 1997, 107, 3032-3041. [CrossRef]

25. Reed, A.E.; Curtiss, L.A.; Weinhold, F. Intermolecular interactions from a natural bond orbital, donor-acceptor viewpoint. Chem. Rev. 1988, 88, 899-926. [CrossRef]

26. Reed, A.E.; Weinhold, F. Natural bond orbital analysis of near Hartree-Fock water dimer. J. Chem. Phys. 1983, 78, 4066-4073. [CrossRef]

27. Wang, K.; Shan, X.; Chen, X. Electron propagator theory study of 2-aminoethanol conformers. J. Mol. Struct. 2009, 909, 91-95. [CrossRef]

28. Song, L.; Lin, Y.; Wu, W.; Zhang, Q.; Mo, Y. Steric strain versus Hyperconjugative stabilization in ethane congeners. J. Phys. Chem. A 2005, 109, 2310-2316. [CrossRef] [PubMed]

29. Yamamoto, T.; Kaneno, D.; Tomoda, D. The origin of cis effect in 1,2-dihaloethenes: the quantitative comparison of electron delocalizations and steric exchange repulsions. Bull. Chem. Soc. Jpn. 2008, 81, 1415-1422. [CrossRef]

30. Pophristic, V.; Goodman, L. Hyperconjugation not steric repulsion leads to the staggered structure of ethane. Nature 2001, 411, 565-568. [CrossRef] [PubMed]

31. Glendenning, E.D.; Reed, A.E.; Carpenter, J.E.; Weinhold, F. NBO; version 3.1.; Gaussian Inc.: Pittsburg, PA, USA, 2001.

32. Frisch, M.J.; Trucks, G.W.; Schlegel, H.B.; Scuseria, G.E.; Robb, M.A.; Cheeseman, J.R.; Scalmani, G.; Barone, V.; Mennucci, B.; Petersson, G.A.; et al. Gaussian 09; revision A.02; Gaussian, Inc.: Wallingford, CT, USA, 2009.

33. Garza, A.J.; Osman, O.I.; Scuseria, G.E.; Wazan, N.A.; Khan, S.B.; Asiri, A.M. Nonlinear optical properties of DPO and DMPO: A theoretical and computational study. Theor. Chem. Acc. 2013, 132, 1384-1390. [CrossRef]

34. Kaatz, P.; Donley, E.A.; Shelton, D.P. A comparison of molecular hyperpolarizabilities from gas and liquid phase measurements. J. Chem. Phys. 1998, 108, 849-856. [CrossRef]

35. Aziz, S.G.; Elroby, S.A.K.; Hilal, R.H.; Osman, O.I. Theoretical and computational studies of conformation, natural bond orbital and nonlinear optical properties of $c i s-N$-phenylbenzohydroxamic acid. Comput. Theor. Chem. 2014, 1028, 65-71. [CrossRef]

36. Garza, A.J.; Scuseria, G.E.; Khan, S.B.; Asiri, A.M. Assessment of long-range corrected functionals for the prediction of non-linear optical properties of organic materials. Chem. Phys. Lett. 2013, 575, 122-125. [CrossRef]

37. Champagne, B.; Perpete, E.A.; Jacquemin, D.; van Gisbergen, S.J.A.; Baerends, E.J.; Soubra-Ghaou, C.; Robins, K.A.; Kirtman, B. Assessment of conventional density functional schemes for computing the dipole moment and (hyper)polarizabilities of push pull $\pi$-conjugated systems. J. Phys. Chem. A 2000, 104, 4755-4763. [CrossRef]

38. Solomon, R.V.; Veerapandian, P.; Vedha, S.A.; Venuvanalingam, P. Tuning nonlinear optical and optoelectronic properties of vinyl coupled triazene chromophores: A density functional theory and time-dependent density functional theory investigation. J. Phys. Chem. A 2012, 116, 4667-4677. [CrossRef] [PubMed] 
39. Loboda, O.; Zalesny, R.; Avramopoulos, A.; Luis, J.M.; Kirtman, B.; Tagmatarchis, N.; Reis, H.; Papadopoulos, M.G. Linear and nonlinear optical properties of [60]fullerene derivatives. J. Phys. Chem. A 2009, 113, 1159-1170. [CrossRef] [PubMed]

40. Thanthiriwatte, K.S.; Nalin de Silva, K.M. Non-linear optical properties of novel fluorenyl derivatives-ab initio quantum chemical calculations. J. Mol. Struct. Theochem. 2002, 617, 169-175. [CrossRef]

41. Sriyanka Mendis, B.A.; Nalin de Silva, K.M. A comprehensive study of non-linear optical properties of novel charge transfer molecular systems. J. Mol. Struct. Theochem. 2004, 678, 31-38. [CrossRef]

42. Asiri, A.M.; Khan, S.A.; Al-Amoudi, M.S.; Alamry, K.A. Synthesis, characterization, absorbance, fluorescence and non-linear optical properties of some donor acceptor chromophores. Bull. Korean Chem. Soc. 2012, 33, 1900-1906. [CrossRef]

43. Becke, A.D. Density-functional exchange-energy approximation with correct asymptotic behavior. Phys. Rev. 1988, 38, 3098-3100.

44. Lee, C.; Yang, W.; Parr, G. Development of the Colle-Salvetti correlation-energy formula into a functional of the electron density. Phys. Rev. B 1988, 37, 785-789. [CrossRef]

45. Ditchfield, R.; Hehre, W.J.; Pople, J.A. Self-consistent molecular-orbital methods. IX. An extended gaussian-type basis for molecular-orbital studies of organic molecules. J. Chem. Phys. 1971, 54, 724-728. [CrossRef]

46. Dunning, T.H. Gaussian basis sets for use in correlated molecular calculations. I. The atoms boron through neon and hydrogen. J. Chem. Phys. 1989, 90, 1007-1023. [CrossRef]

47. Berry, R.S.; Davidovits, P.; McFadden, D.L. Alkali Halide Vapors; Academic Press: New York, NY, USA, 1979.

48. Fukui, K. The path of chemical reactions-The IRC approach. Acc. Chem. Res. 1981, 14, 363-368. [CrossRef]

49. Dennington, R.; Keith, T.; Millam, J. GaussView; version 5; Semichem Inc.: Shawnee Mission, KS, USA, 2009.

50. Geomodeling in GeoGraphix. Available online: http://www.chemcraftprog.com (accessed on 13 May 2015).

(C) 2015 by the authors; licensee MDPI, Basel, Switzerland. This article is an open access article distributed under the terms and conditions of the Creative Commons by Attribution (CC-BY) license (http:/ / creativecommons.org/licenses/by/4.0/). 